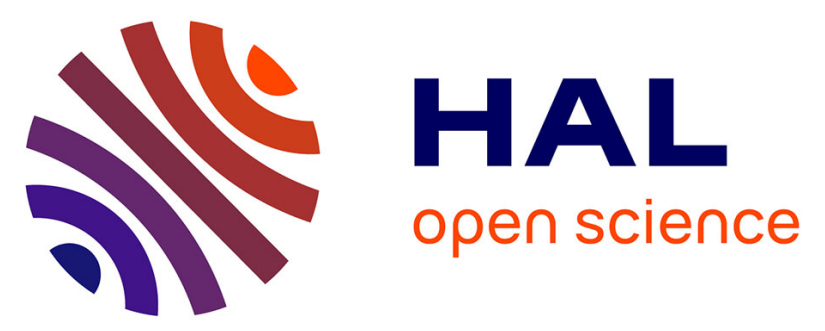

\title{
A Continuous Lumping Model for Hydrocracking on a Zeolite Cata- lysts: Model Development and Parameter Identification
}

Per Julian Becker, Benoit Celse, Denis Guillaume, Victor Costa, Luc Bertier, Emmanuelle Guillon, Gerhard Pirngruber

\section{To cite this version:}

Per Julian Becker, Benoit Celse, Denis Guillaume, Victor Costa, Luc Bertier, et al.. A Continuous Lumping Model for Hydrocracking on a Zeolite Cata- lysts: Model Development and Parameter Identification. Fuel, 2016, 164, pp.73-82. 10.1016/j.fuel.2015.09.057 . hal-01231059

\section{HAL Id: hal-01231059 \\ https://hal.science/hal-01231059}

Submitted on 19 Nov 2015

HAL is a multi-disciplinary open access archive for the deposit and dissemination of scientific research documents, whether they are published or not. The documents may come from teaching and research institutions in France or abroad, or from public or private research centers.
L'archive ouverte pluridisciplinaire HAL, est destinée au dépôt et à la diffusion de documents scientifiques de niveau recherche, publiés ou non, émanant des établissements d'enseignement et de recherche français ou étrangers, des laboratoires publics ou privés. 


\section{A Continuous Lumping Model for Hydrocracking on a Zeolite Cata- 2 lysts: Model Development and Parameter Identification}

3 Per Julian BECKER, Benoit CELSE*, Denis GUILLAUME, Victor COSTA, Luc BERTIER, Emman-

4 uelle GUILLON, Gerhard PIRNGRUBER

IFP Energies nouvelles-établissement de Lyon Rond-point de l'échangeur de Solaize, BP 3, 6936o Solaize.

*benoit.celse@ifp.fr

KEYWORDS Hydrocracking, Kinetic Modeling, Continuous Lumping, Sensitivity Study

\section{Introduction}

11 The rapid decline in conventional light crude oil resources [1], combined with the increasing demand for middle distillates (i.e. Kerosene and Gasoil cuts) [2,3] have made Hydrocracking an increasingly attractive option for upgrading of Vacuum Gas Oil (VGO) residue. The VGO cut is characterized by a high True Boiling Point (i.e. high percentage of $>370^{\circ} \mathrm{C}$ cut) [4]. It frequently contains relatively high amounts of organic nitrogen and sulfur, which are undesirable in the final products (ie.g. diesel, fuel oil). The purpose of hydrocracking units is the transformation of VGO to valuable middle distillate fractions, conforming to ever more stringent product quality specifications[5].

The hydrocracking (HCK) process involves the breaking up of large hydrocarbons by $\beta$-scission, hydrogenation of aromatic rings, as well as PCP-isomerization. The removal of organic nitrogen and sulfur by hydrodenitrogenation (HDN) and hydrodesulfurization (HDS) reactions are another important function of a HCK unit [5]. A hydrocracking unit often uses a zeolite catalyst with an acid and a metallic site [6]. A good general description of the mechanism is given by Weitkamp [7].

The reaction mechanism of such bifunctional catalysts has been the object of a number of past $[8,9]$ and recent studies [10-16]. Many of these studies are focused on model feeds, such as Fisher-Tropsch wax [14] or n-alkane mixtures [15]. Maya residue [17] and Athabasca bitumen derived VGO [16] are among the industrial feedstocks used for model development.. 
Hydrocracking of non-conventional and non-crude feedstocks is becoming an increasingly active area of research. This

study is focused on the development of a hydrocracking model based on traditional VGO residues.

Even if HCK is a well-established tool in the petroleum refining industry [5], the continuing improvement in analytic techniques and computational capabilities have led to a number of recent developments in this field [5,21,22]. Process modeling, in particular, has been a major factor in advancing the understanding the operation of hydrocracking units [23]. There are two main motivations for developing hydrocracking models: 1) obtaining robust predictions of the performance of HCK units, which can be used to guide process design and optimization, and 2) obtaining a more nuanced understanding of the underlying physico-chemical processes to guide basic research and development of new catalysts and/or process designs.

Accurate and robust simulation of residue (i.e. $>370^{\circ} \mathrm{C}$ cut) conversion, yield structure in terms of standard cuts, and simulated distillation (SIMDIS) is required by a hydrocracking model. The hydrogen consumption, generation of gases $\left(C_{3} \& C_{4}\right)$, as well as a number of product qualities should also be well predicted. An advanced HCK model should be validated for a wide range of operating conditions and for different feeds in order to have the explanatory capabilities. When the tuning parameters for a complex model, including mechanistic considerations as well as empirical aspects, are adjusted for a very restrained database, they are only valid within this limited range. In this case little or no additional information regarding the underlying physic-chemical processes of the system can be gained, regardless of the level of detail of the model. Simple empirical correlations can often give equivalent results than a continuous lumping model within the restrained range of applicability. This work aims to show that a continuous lumping model can be validated for a large range of operating conditions (temperature, contact time, $\mathrm{H}_{2} / \mathrm{HC}$ ), and feedstocks (residue content, nitrogen content).

Comprehensive reviews of the recent development in hydrocracking models have been compiled by Ancheyta and Elizade [21,24]. A number of different approaches are used, depending on the available data and intended application of the model. Discrete lumping models, which use dedicated correlations for the reactivity of each lump, are among the simplest option. First developed by Qader and Hill [25], these models have been widely used [21,22]. The lumps can represents specific cuts or pseudo components [26]. Continuous lumping models offer a much finer resolution of the feed. They consider the hydrocarbon mixture to be a continuous distribution along an internal coordinate (most commonly True Boiling Point, TBP) $[21,22,24,27,28]$. A more detailed description of the reaction network can be achieved by decomposition of the feed into a number of lumps, each distributed along TBP [22]. Other modeling approaches include the use 
approach, which is not based on an understanding of the underlying chemical kinetics. These powerful models can be used when large amounts of data are available. Microkinetic modeling, such as the single events approach, is based on the reconstruction of the feed into its individual molecules. A large reaction network with thousands of possible reaction pathways is then constructed. These models require a detailed understanding of the chemical kinetics and feed composition. A large amount of computational resources is also required.

The data fitting procedure and statistical analysis of model parameters for a continuous lumping model is presented in this work. The paper is structured as follows: The experimental setup of the pilot plant and the databases is presented in section 2. Details of the continuous lumping model used here are given in section 3. This is followed by a description of the parameter fitting procedure, as well as a model evaluation in sections 4 and 5 . A statistical analysis of the model parameters is given in section 6 .

2. Materials \& Methods

\subsection{Process Description}

Industrial hydrocracking operations are generally a two-step process $\left(R_{1}+R_{2}\right)$. The second step $\left(R_{2}\right)$ is considered separately in this study.The main HCK reactor, with a zeolite catalyst follows an hydrotreatment reactor. The first reactor (R⿺) uses a catalyst designed to remove organic nitrogen and sulfur, hydrogenate aromatic compounds, and remove metallic impurities. These catalysts are much less susceptible to poisoning than the zeolite-based HCK catalysts. Nitrogen- and sulfur-containing compounds, as well as metals are known to inhibit zeolite catalysts [5]. This allows the more fragile zeolite catalyst in the second reactor $\left(\mathrm{R}_{2}\right)$ to perform the main hydrocracking reaction. The main purpose of the HCK catalyst $\left(\mathrm{R}_{2}\right)$ is the breaking up of large hydrocarbon atoms contained in the VGO residue, in order to obtain the more valuable middle distillate cuts. Two types of tests were used in the calibration and evaluation databases: 1) pretreatment $\left(\mathrm{R}_{1}\right)$ and hydrocracking $\left(\mathrm{R}_{2}\right)$ in a single step, and; 2 ) separate pretreatment $\left(\mathrm{R}_{1}\right)$. These two cases are illustrated in Figure 1

In the first case, the gases produced in $\mathrm{R}_{1}\left(\mathrm{H}_{2} \mathrm{~S}, \mathrm{NH}_{3}\right.$, hydrocarbon gasses) are carried over in the feed entering $\mathrm{R}_{2}$. The total mass entering $\mathrm{R}_{2}$, with respect to the feed of $\mathrm{R}_{1}$, is equal to the sum of the mass entering two-step process and the hydrogen consumption in R1.. The total yield of the two reactors is then equal to the mass of the feed (R1) and the hydro-

81 gen consumption in the two reactors ( $\mathrm{R}_{1}$ and $\left.\mathrm{R}_{2}\right)$. 
In the second case, the gases are separated from the effluent of the pretreatment reactor, which is analyzed and stored for subsequent use in a hydrocracking test. The feed entering $\mathrm{R} 2$ is therefore $100 \%$ liquid. Aniline and dimethyldisulfide (DMDS) additives are added in order to include the effect of $\mathrm{NH}_{3}$ and $\mathrm{H}_{2} \mathrm{~S}$ on the zeolite catalyst. This mass is subsequently subtracted from the effluent, giving a total yield of sum of the mass of the feed (R2) and the hydrogen consumption (excluding $\mathrm{H}_{2}$ used up in the generation of $\mathrm{H}_{2} \mathrm{~S}$ from DMDS and $\mathrm{NH}_{3}$ from Aniline). This setup allows the influence of feed nitrogen content to be studied independent of other feed characteristics.

The sulfur and nitrogen contents in the liquid stream entering $R_{2}$ are subsequently referred to as $S_{R_{2}}$ and $N_{R_{2}}$, respectively. The nitrogen and sulfur content entering $R 1$ are referred to as $N_{R_{1}}$ and $S_{R_{1}}$. In the case of a pre-treated feed, the equivalent nitrogen content due to aniline additive is used instead.

\subsection{The Pilot Plant}

The experimental runs presented in this study were performed in a pilot unit at IFP Energies Nouvelles, Solaize, France. The hydrocracking step was performed on a commercial NiMoP-zeolite catalyst. Various commercial HDT catalysts were used for the pretreatment step. Total catalyst volume in both reactors is $50 \mathrm{~cm}^{3}$. The plant consists of a number of fixed beds, down-flow reactors, designed to mirror the operating conditions in industrial hydrocracking units. Unlike industrial units, which operate in adiabatic mode, the pilot plant operates in isothermal conditions. Temperature is controlled along the reactor. The units were run in continuous operation. Individual mass balances were taken for up to 12 hours, after temperatures, pressures, flow rates, and effluent properties were stabilized. A series of mass balances with different operating conditions were thus taken from each experimental run. Each mass balance corresponds to a single experimental point.

101 Analyses were performed on the feedstocks, the liquid and gaseous effluents, as well as a sample taken on the effluent of the pretreatment reactor (where applicable, see Figure 1 and Figure 2). The most relevant measurements to this study were the analysis of the feed sulfur and nitrogen contents, the partial pressures of $\mathrm{NH}_{3}, \mathrm{H}_{2} \mathrm{~S}$, and $\mathrm{H}_{2}$ gasses, as well as the simulated distillation.

\subsection{The Calibration \& Validation Databases}

A calibration database, consisting of 52 mass balances, was compiled. Feed characteristics and operating condition were chosen to correspond to the ones encountered in industrial hydrocracking units. This database was used for the identifi- 
mass balances was used to validate the model performance. The feed nitrogen and sulfur content of the two databases is shown in Figure 3. Different feeds of Iranian or Arabian origin were used at varying levels of pretreatment (R1). For about half $(\mathrm{n}=31)$ of the experimental runs, pretreatment and hydrocracking were performed in a single step, corresponding to Figure 1. The remaining runs $(n=43)$ were performed in separate steps, corresponding to Figure 2.

The range of the main operating conditions, temperature $\left({ }^{\circ} \mathrm{C}\right)$, hydrogen to hydrocarbon ratio $\left(\mathrm{H}_{2} / \mathrm{HC}, \mathrm{StdL} / \mathrm{L}\right)$, and Liquid Hourly Space Velocity $\left(\mathrm{LHSV}, \mathrm{h}^{-1}\right)$ is given in Figure 4 . The residue $\left(>370^{\circ} \mathrm{C}\right)$ cut in the feed of the zeolite catalytic bed $\left(R_{2}\right)$ and its conversion, $X_{370+}=100^{*}\left(1-Y_{370+, \text { out }} / Y_{370+\text { in }}\right)$ are given in Figure 5 to give an overview of the performance of the experimental runs.

The range of the residual organic nitrogen in the feed is o - $154 \mathrm{ppm}$. Four runs in the calibration database had contained no detectable organic nitrogen; these are not shown in Figure 3 because of the log scale. The sulfur content is not used in the modeling because it has been found to have negligible influence on hydrocracking reactions on a zeolite catalyst. The $\mathrm{NH}_{3}$ entering $\mathrm{R}_{2}$, due to the feed nitrogen content of the pretreatment reactor or the aniline additive was varied between 570 and $2800 \mathrm{ppm}$, with one run performed at a very high value of $5000 \mathrm{ppm}$. The nitrogen and sulfur content in the $R_{1}$ and $R_{2}$ feeds of the validation database are within the range of the validation database. The variations in the feeds must be taken into account by the model. Using a continuous rather than a discrete lumping approach allows the full distribution (SIMDIS) of the feed rather than a limited number of lumps to be used as the model input.

Most tests were performed at a standard ratio of $\mathrm{H}_{2}$ gas to hydrocarbon flowrates $\left(\mathrm{H}_{2} / \mathrm{HC}\right)$ of $1000 \mathrm{~L} / \mathrm{L}$ (std) and a total pressure of 140 bar. Four runs in the calibration database were performed at 100 bar, while four runs in the validation database were performed at 160 bar. The temperature and LHSV were varied between $370-401^{\circ} \mathrm{C}$ and $1.3-4.2 \mathrm{~h}^{-1}$ in the calibration database. The validation tests generally fall within the same range, with the exception of four runs with a LHSV of $0.9 \mathrm{~h}^{-1}$, and one test at a very low temperature of $362^{\circ} \mathrm{C}$.

The residue ( $>370^{\circ} \mathrm{C}$ cut) of the feed of R2 falls in a relatively narrow range of between $67-84 \%$, with two validation tests at around $50 \%$, corresponding to very high levels of pretreatment. The conversion $\left(\mathrm{X}_{370+}\right)$, on the other hand, covers the complete range that can be achieved in a hydrocracking reactor, i.e. up to $100 \%$.

Measurements for the composition of the residue $\left(>370^{\circ} \mathrm{C}\right)$ cut of the calibration feeds $(\mathrm{R} 2)$, in terms of paraffin $(\mathrm{P})$, naphtene (N) and aromatic (A) compounds are available for the pretreated feeds (see Figure 2). This shows that the composition of the feeds used in this study does not vary very much. The residue cut of the feeds have an aromatics content of 10 to $37 \%$, with most feeds close to $30 \%$. 
139

140

$$
\theta=\frac{T B P-T_{\min }}{T_{\max }-T_{\min }}
$$

Where:

TBP True Boiling Point $\left({ }^{\circ} \mathrm{C}\right)$

$T_{\min } \quad-7.6^{\circ} \mathrm{C}\left(\mathrm{TBP}\right.$ of $\left.\mathrm{C}_{4} \mathrm{H} 10\right)$

$T_{\max } \quad 700^{\circ} \mathrm{C}$

It is important to note that the main cracking mechanism is $\beta$-scission of saturated hydrocarbon chains or cycles. $\beta$ scissions on a straight chain result in two smaller molecules with lower boiling points. For endo-cyclic $\beta$-scissions of cycloalkanes (i.e. ring opening), a single, saturated alkane chain is formed. This results in a change in TBP, but no reduction in size of the molecule. However, a number of different reaction types occur during the hydrocracking process. Isomerization reactions change the branching degree of a hydrocarbon, which can increase or decrease the TBP of the reaction product. Aromatic compounds are hydrogenated, forming saturated cycloalkanes (naphtenes). Hydrogenation of aromatic ringsis also accompanied by a decrease in boiling point. ing a decrease in the TBP of the mixture are lumped together to give an apparent reaction rate. A more detailed, multifamily approach, which treats the reaction pathways between aromatic, naphtene, and paraffins explicitly, has been pre- 
161 composition.. Such analyses are rarely available in an industrial context. A model capable of predicting the composition of 162 the effluent is therefore of limited usefulness for the hydrocracking units design and optimization. However, they are 163 useful in a research and development context. They allow the characterization of the chemical reaction pathways and 164 activity of a catalyst. This can lead to a better understanding of the underlying phenomena which can consequently be 165 used to guide future developments.

166 The model presented here has been developed to capture the effect of the main operating parameters and feed condi167 tions in order to predict the yield structure of the hydrocracker. 
171 The feed simulated distillation (SIMDIS is a cumulative mass distribution. The associate continuous distribution, $\mathrm{c}(\theta, \mathrm{t})$, 172 can be split up into a number of intervals $\mathrm{i}$, with $\Delta \theta_{\mathrm{i}}=\left[\theta_{i-}, \theta_{i+}\right]$, with $\theta_{i-}<\theta_{i+}$. The discrete concentration in each inter173 val, $C_{i}$, is given by:

$$
C_{i}=\int_{\theta_{i-1}}^{\theta_{i-1}} c(\theta, t) d \theta
$$

Each interval is represented by $\theta_{i}$. The mass balance for each interval $i$ is:

$$
\frac{\Delta C_{i}}{\Delta t}=-R_{i, o u t}+R_{i, \text { in }}
$$

The mass being eliminated from the interval $i, R_{i, \text { iout }}$ is due to molecules being cracked. This results in a lower TBP. The mass $R_{i, i n}$ being added to the interval $i$, is due to the cracking of heavier hydrocarbons (i.e. in classes with $\theta_{j}>\theta_{i}$ ). The mass $C_{i}$ tively.

$$
\frac{\partial c(\theta, t)}{\partial t}=-r_{\text {out }}(\theta, t)+r_{\text {in }}(\theta, t)
$$

An expansion of the elimination $\left(r_{\text {out }}\right)$ and generation $\left(r_{i n}\right)$ terms leads to:

$$
\begin{aligned}
& \frac{\partial c(\theta, t)}{\partial t} \\
& =-k_{\mathrm{T}} f_{X}(\theta) I_{N}(t) C(\theta, t) \\
& +\int_{\theta}^{\infty} k_{\mathrm{T}} f_{X}(\theta) I_{N}(t) C(\theta, t) g\left(\theta, \theta^{*}\right) d \theta^{*}
\end{aligned}
$$

183 Where:

$c(\theta, t) \quad$ Mass fraction at $\operatorname{TBP} \theta$, and time $\mathrm{t}$

$f_{X}(\theta) \quad$ Reactivity function 
$I_{N} \quad$ Nitrogen inhibition term

$k_{T} \quad$ Pre-factor at temperature T

$g\left(\theta, \theta^{*}\right) \quad$ Yield distribution function

184

185 The yield distribution, $g\left(\theta, \theta^{*}\right)$, and reactivity function, $f_{X}(\theta)$, do not change along the reactor (for isothermal operation) 186 and are therefore calculated a priori.

187 A gamma function was chosen for the reactivity function and a beta distribution was chosen for the yield distribution. 188 These two functions are very flexible regarding the shapes they can take [22]. They were chosen over the mode common 189 Gaussian and exponential distribution to give additional degrees of freedom to the model. The functions are given in 190 equations (4) and (5) respectively Both functions take two tuning parameters.

$$
\begin{gathered}
f(\theta)=\theta^{A} e^{-B \theta} \\
g\left(n, n^{*}\right)=\left(\frac{n}{n^{*}}\right)^{\alpha_{y}-1}\left(1-\frac{n}{n^{*}}\right)^{\beta_{y}-1}
\end{gathered}
$$

191 Where:

$\begin{array}{cl}n & \text { Number of carbon atoms in compound undergoing cracking } \\ n^{*} & \text { Number of carbon atoms in cracking product } \\ \alpha_{y}, \beta_{y} & \text { Model parameters for yield distribution } \\ A, B & \text { Model parameters for reactivity }\end{array}$

The yield distribution is defined in terms of carbon numbers (n), rather than TBP $(\theta)$ in order to ensure mass conservation without an additional normalization term. The model equation (3), however, is defined in terms of TBP $(\theta)$. The 194 transformation of carbon number to TBP, $n=f(\theta)$, is performed according to the TBP of normal paraffins.

195 An Arrhenius term was included in the pre-factor $\left(k_{T}\right)$ to account for the effect of temperature variations.

$$
k_{T}=k_{0} \exp \left[-\frac{E_{a}}{R_{g}}\left(\frac{1}{T}-\frac{1}{T_{\text {ref }}}\right)\right]
$$

196 With:

$$
\begin{array}{cl}
k_{o} & \text { Pre-factor,model parameter } \\
E_{a} & \text { Activation energy,model parameter (in kJ mol }{ }^{-1} \text { ) } \\
T & \text { Reaction temperature (in K) } \\
T_{r e f} & \text { Reference temperature (in K) }
\end{array}
$$




$$
R_{g} \quad \text { Gas constant }\left(8.314 \mathrm{~J} \mathrm{~K}^{-1} \mathrm{~mol}^{-1}\right)
$$

The continuous expression (equation 3) is discretized at equally spaced TBP intervals of $5^{\circ} \mathrm{C}$. The resulting set of ODEs is solved by the well-known LSODE solver. The model was implemented in object-oriented FORTRAN.

\subsection{Hydrogen Consumption}

The total mass flowrate of the effluent is higher than the mass flowrate of the (HCK) feed because of the hydrogen added in process. Estimation of the hydrogen consumption is necessary in order to determine the total yield of the hydrocracking reaction. Two hydrogen atoms (i.e. one $\mathrm{H}_{2}$ ) are added in each $\beta$-scission reaction. The total number of cracking reactions is estimated via a correlation of the feed and effluent densities, i.e. $H_{2, \beta}=f\left(d_{154, f e e d}, d_{154, e f f}\right)$. This correlation is based on the n-d-m method (ASTM D-3238 [34]) is used.

Furthermore, three $\mathrm{H} 2$ molecules are added for each full hydrogenation of an aromatic ring: $H_{2, A}=3 *\left(C_{A, \text { feed }}-C_{A, \text { eff }}\right)$. Measurements of the total amount of aromatic carbon atoms in the feed are available, and the extent of the hydrodearomatisation reaction is estimated by a dedicated model not detailed here. The hydrogen added by the hydrodenitrogenation and hydrodesulfurization reactions is also taken into account.

\subsection{Inhibition Terms}

Zeolite catalysts are known to be inhibited by the presence of $\mathrm{NH}_{3}$ gas[6]. An inhibition term $\left(I_{N}\right)$, based on the nitrogen content in the feed of $\mathrm{R}_{1}\left(N_{R_{1}}\right)$ was therefore introduced in the model. The nitrogen in the feed of $\mathrm{R}_{1}$ is mostly transformed to $\mathrm{NH}_{3}$, which is carried over to $\mathrm{R} 2$. The inhibition term is therefore derived from an estimation of the partial pressure of $\mathrm{NH}_{3}$ gas in the reactor, given in equation (9).

$$
\frac{1}{\mathrm{ppNH}_{3}} \propto\left(\frac{H_{2} H_{C}}{P_{t o t} N_{R 1}}\right)
$$

The residual nitrogen content in the feed of $\mathrm{R}_{2}\left(N_{R_{2}}\right)$ does also exhibit an inhibition effect on the zeolite catalyst. The nitrogen containing organic compounds adsorb on the acidic sites of the catalyst. These sites are therefore no longer available to perform hydrocracking reactions, until the nitrogen has been converted into $\mathrm{NH}_{3}$ gas. The nitrogen containing compounds remaining after a hydrotreatment step are generally very difficult to break down. The complete inhibition term used in this model is given in equation (10). A total of four tuning parameters allow the adjustment of this term to experimental data. 


$$
I_{N}=\left[\frac{1}{\left(1+\alpha_{N R 2} N_{R 2}^{\beta_{N R 2}}\right)}\right]\left[\frac{1}{1+\alpha_{N R 1}\left(\frac{H_{2} H_{C}}{P_{t o t} N_{R 1}}\right)^{\beta_{N R 1}}}\right]
$$

With:

$\begin{array}{cl}\mathrm{H}_{2} \mathrm{H}_{\mathrm{C}} & \text { Volumetric ratio of } \mathrm{H} 2 \text { to hydrocarbon feed (in std } \mathrm{L} / \mathrm{L} \text { ) } \\ P_{\text {tot }} & \text { Total pressure in } \mathrm{R} 2 \text { (in bar) } \\ N_{R 1} & \text { Organic nitrogen in feed of } \mathrm{R} 1 \text { (in ppm) } \\ \alpha_{N R 2}, \beta_{N R_{2}} & \text { Model parameters } \\ N_{R 2} & \text { Organic nitrogen in feed of } \mathrm{R} 2 \text { (in ppm) } \\ \alpha_{N R 2}, \beta_{N R_{2}} & \text { Model parameters }\end{array}$

\subsection{Generation of Hydrocarbon Gas}

The generation of hydrocarbons smaller than $C_{5}$ is treated separately in this model. It has been observed that the pro223 cess of generating these light gases is rather different and cannot be modeled by the same continuous yield distribution used for the simulation of the cracking of heavier hydrocarbons. A separate term, $g(\theta, G A S)$, was therefore introduced in the yield distribution.

$$
g(\theta, G A S)=\alpha_{g a s} \theta^{\beta_{g a s}} e^{-\theta}
$$

This term, shown in equation (11), uses a separate gamma function to estimate the total yield of $\mathrm{C}_{1}-\mathrm{C}_{4}$ gas by cracking of a hydrocarbon with TBP $\theta$. The additional model parameters $\left(\alpha_{g a s}\right.$ and $\left.\beta_{g a s}\right)$ give further flexibility to the model.

The redistribution between $\mathrm{C}_{3}$ and $\mathrm{C}_{4}$ gasses are calculated using a dedicated correlation, which has been fitted separately using a separate calibration database. Zeolite catalysts, such as the one used in this study, generate negligible amounts of $C_{1}$ and $C_{2}$ gas. This is because the $\beta$-scission reaction mechanism cannot crack a hydrocarbon chain at the ends.

\section{Parameter Identification}

The continuous lumping model presented in section 2.1 contains 12 tuning parameters. These parameters were identified using the calibration database presented in section 3.3. An objective function for a set of parameters $(\beta)$ was constructed, defined in equation (9), from the square difference between the experimental measurements ( $y$ ) and the simulation results $f(x, \beta)$. Weights $(w)$ were applied different components of the objective function. 


$$
J=\frac{1}{2}^{t}(y-f(x, \beta)) w(y-f(x, \beta))
$$

With:

$$
\begin{array}{cl}
J & \text { Objective function } \\
y & \text { Experimental observations (vector) } \\
f(x, \beta) & \text { Organic nitrogen in feed of Ri (in ppm) } \\
x & \text { Model inputs (vector) } \\
\text { B } & \text { Model parameters } \\
w & \text { Weights (diagonal matrix) }
\end{array}
$$
SIMDIS (9 points), were used in the objective function, according to following weights $(w)$ :

$\begin{array}{llll}241 & \cdot & \text { Naphtha }\left(<150^{\circ} \mathrm{C} \text { cut }\right) & 3 \\ 242 & \cdot & \text { Kerosene }\left(150-250^{\circ} \mathrm{C} \text { cut }\right) & 6 \\ 243 & \cdot & \text { Gasoil }\left(250-370^{\circ} \mathrm{C} \text { cut }\right) & 6 \\ 244 & \cdot & \text { Middle distillates }\left(150-370^{\circ} \mathrm{C} \text { cut }\right) & 10 \\ 245 & \cdot & \text { Residue }\left(>370^{\circ} \mathrm{C} \text { cut }\right) & 10 \\ 246 & \cdot & \text { SIMDIS }(10-90 \%) & 0.01 \\ 247 & \cdot & \text { Gas yield }(\mathrm{C} 1-\mathrm{C} 4) & 10 \\ 248 & \cdot & \text { Total yield } & 1\end{array}$

249 It is important to note that the error in SIMDIS is expressed in terms of ${ }^{\circ} \mathrm{C}$, while the other errors are expressed in terms 250 of percentages. The former are an order of magnitude higher than the latter for a comparable fit of the model. A low 251 weight was therefore chosen in order to obtain the same order of magnitude for all observables.

The DN2FB FORTRAN optimization routine, part of the PORT library (Bell Labs) was used for parameter identification [35]. This routine uses a Levenberg-Marquardt least squares algorithm to find the gradients of the objective function. The target function is highly non-linear. The optimized set of parameters was found to be highly dependent on the initial parameters, which implies convergence to local minima, rather than global ones in some cases. Optimizations were therefore performed for a set of 96 randomly chosen initial parameters. Optimizations were performed on the highperformance cluster at IFP Energies Nouvelles, Solaize, France. The parameters of the case which converged to the lowest value of the objective function was retained.

This procedure does not guarantee convergence to the global minimum, it does, however, at the very least provide a good local minimum. The use of more advanced, global algorithms (i.e. genetic / global response surface algorithms) is far 
academic research context.The approach used in this study is better suited for practical applications, where a the model

parameters for a new catalyst needs to be identified rapidly. The comparison of different optimization algorithms is per-

\section{Model Validation}

The objective of the construction of a continuous lumping model for a hydrocracking process is the accurate estimation

of yield structure and simulated distillation for a range of operating conditions. Estimation of the yield structure, in terms of standard cuts, is necessary in order to perform process design and optimization. It is common to design a hydrocracking process in order to maximize the conversion of the residue cut $\left(\mathrm{X}_{370^{+}}\right)$and the yield of the middle distillates $(150$ $250^{\circ} \mathrm{C}$ cut). The production of hydrocarbon gases $\left(\mathrm{C}_{1}-\mathrm{C}_{4}\right)$ is generally undesirable [5].

The temperature of an industrial hydrocracking reactor is often adjusted to give a desired conversion $\left(\mathrm{X}_{37^{+}+}\right)$. The rela-

tionship between $\mathrm{X}_{37^{+}}$and yield structure is therefore of particular interest. For a given feed and catalyst, this relationship is relatively independent of reactor temperature. Simulations are run in two different modes:

1) iso-T: the real (measured) reactor temperature is used;

2) iso-RS: the temperature is adjusted such that the simulated residue content equals the experimental measured value.

Good estimation of the SIMDIS of the effluent is necessary in order to calculate a number of product qualities for the individual cuts (e.g. d154, octane number, viscosity index, cetane index). This is done by dedicated correlations, based on the modeled SIMDIS.

Parity graphs, showing the agreement of simulation results and experimental measurements have been constructed for iso-T and iso-RS modes.

\subsection{Iso-T mode}

The results for residue conversion $\left(\mathrm{X}_{370+}\right)$ and middle distillate yield in iso-T mode are shown in Figures 8 and 9.

The residue conversion is well predicted for the entire range, i.e. 15 to $100 \%$. Some data points, particularly for the validation database and/or for very high $\mathrm{X}_{370^{+}}$, tend to be somewhat under-predicted. The middle distillate yield $\left(150-370^{\circ} \mathrm{C}\right)$ is very well predicted in iso-T mode. All points, with the exception of one point in the validation database, fall within an error band of $\pm 5 \%$. A summary of the mean absolute errors for a number of indicators is shown in Table 1 . 
The mean absolute errors for $\mathrm{X}_{370_{+}}$and yield structure for both, the calibration and validation database are very good for

experimental runs with $\mathrm{X}_{370^{+}}<90 \%$. The errors are slightly higher but remain acceptable for the validation points. The points with very high residue conversion are less well predicted by the model. It is, however, important to note that industrial hydrocracking units rarely operate at conversions higher than 90\%. These points are therefore of somewhat limited interest.

The possible reasons for this behavior are that the calibration database contained only two data points with $\mathrm{X}_{37^{+}+}>90 \%$.

The shape of the reactivity function in this region is therefore not sufficiently sensitized. The other reason is related to the fact that the SIMDIS becomes very steep around $370^{\circ} \mathrm{C}$. This amplifies the error of residue ( $>370^{\circ} \mathrm{C}$ cut) yield, i.e. the point at which the SIMDIS and intersects the $370^{\circ} \mathrm{C}$ line. The mean absolute errors of hydrogen consumption and total yield show that the model ensures mass conservation and predicts the correct mass flowrates.

\subsection{Iso-RS mode}

A more detailed analysis is provided for the simulation results in iso-T mode. The simulation results for residue $\left(>370^{\circ} \mathrm{C}\right.$ cut) yield and thus $\mathrm{X}_{37^{+}+}$, are fitted to experimental measurements in this mode. The yield structure of the model is expected to improve with respect to iso-T mode. Figure 10 shows the middle distillate $\left(150-370^{\circ} \mathrm{C}\right.$ cut $)$ yield. Kerosene $(150-$ $250^{\circ} \mathrm{C}$ cut $)$ and gasoil $\left(250-370^{\circ} \mathrm{C}\right.$ cut $)$, which make up the middle distillate are shown in Figures 11 and 12 respectively.

The middle distillate $\left(150-370^{\circ} \mathrm{C}\right.$ cut $)$ yield is better predicted than in iso-T mode for points with $\mathrm{X}_{370+}<90 \%$. The majority of points fall within the $\pm 2 \%$ error band. The high conversion points, on the other hand, are less well predicted in isoRS mode than in iso-T mode. The parity graphs for the gasoil and kerosene yields show that the error in middle distillate comes mainly from the $250-370^{\circ} \mathrm{C}$ cut. Kerosene $\left(150-250^{\circ} \mathrm{C}\right.$ cut $)$ yield is well predicted, even for elevated residue conversion. The gasoil $\left(250-370^{\circ} \mathrm{C}\right.$ cut) yield is poorly predicted for experimental runs with $\mathrm{X}_{370+}>90 \%$, even though most points fall within a very narrow range $(\sim 20-25 \%)$.

The parity graph for total hydrocarbon gas $\left(\mathrm{C}_{1}-\mathrm{C}_{4}\right)$ shows that the continuous lumping model provides very good simulation results, even for high conversion $\left(\mathrm{X}_{370+}>90 \%\right)$. Only three points of the validation database fall outside the error band of $\pm 1 \%$. A summary of the mean absolute errors for a number of indicators is shown in Table 2 .

The $\Delta \mathrm{T}$ values reported in Table 2 correspond to the mean temperature difference that had to be applied in order to ob313 tain the desired $\mathrm{X}_{37^{+0}}$. As in iso-T mode, the results for the validation database are slightly degraded with respect to the 314 results obtained for the calibration points. A $\Delta \mathrm{T}$ of $2.0^{\circ} \mathrm{C}$ and an error of the yield structure of slightly more than $1 \%$ are well within the accuracy that can be expected from a hydrocracking model. 


\section{Statistical Analysis of Model Parameters}

Statistics were calculated by an in-house code to quantify the relative importance and correlations between the parameters. Standard non-linear optimization routines, such as $\mathrm{DN} 2 \mathrm{FB}$, attempt to determine the optimal set of parameters for the best local minimum of the least-squares objective function. This implies a zero gradient hat around the optimal set of parameters $\beta_{0}$ :

$$
\operatorname{Grad}(J)\left(x, \beta_{0}\right)=0
$$

The Taylor expansion of the objective function $(J)$, around the optimal parameters $\left(\beta_{o}\right)$, given the Hessian $(H)$ gives:

$$
\begin{gathered}
J(x, \beta)=J\left(x, \beta_{0}\right)+\operatorname{Grad}(J)\left(x, \beta_{0}\right)\left(\beta-\beta_{0}\right)+\frac{1}{2}(\beta \\
\left.-\beta_{0}\right)^{\prime} H\left(\beta-\beta_{0}\right) \\
J(x, \beta)=J\left(x, \beta_{0}\right)+\frac{1}{2}\left(\beta-\beta_{0}\right)^{\prime} H\left(\beta-\beta_{0}\right)
\end{gathered}
$$

The Eigenvector $(v)$, with the associated Eigenvalue $(\mu)$ of the Hessian $(H)$ is defined as:

$$
\exists \mu>0 \text { such that } H v=\mu v
$$

A perturbation of $\beta$ in the direction of the Eigenvector $(v)$ gives then, by definition:

$$
\begin{gathered}
\beta=\beta_{0}+\alpha v \\
J(x, \beta)=J\left(x, \beta_{0}\right)+\frac{1}{2} \alpha v^{\prime} H \alpha v \\
J(x, \beta)=J\left(x, \beta_{0}\right)+\frac{1}{2} \mu \alpha^{2}\|v\|^{2}
\end{gathered}
$$

An analysis of the components of the Eigenvector and the magnitude of the associated eigenvalues allows the relative impact of variations of the individual parameters on the target function to be quantified. A small eigenvalue implies a small impact of a variation of the parameters in the direction of the associated Eigenvector; inversely, a large eigenvalue implies a large impact of a perturbation of the parameters in the direction of the associated eigenvector.

The Eigenvectors with their associated Eigenvalues are shown in Table 1. The dominant parameter in the first five Eigenvectors are highlighted to show the parameter with the largest impact on the objective function. This shows that the model is very sensitive to the exponents of the nitrogen inhibition term ( $\beta_{\mathrm{NR} 1}$ and $\beta_{\mathrm{NR}_{2}}$ in equation 8$)$. The parameters of the reactivity function (equation 4 ), the activation energy $\left(\mathrm{E}_{\mathrm{a}}\right)$, and the yield distribution (Equation 7 ) also have a large 
influence on the model behavior. The parameters of the gas distribution (equation 9) have the least influence on the ob333 jective function.

334 The correlation between the individual parameters can be determined from the symmetry in the Eigenvectors. This is 335 shown in Table 4 , higher values strong correlations. This table shows that the pre-exponential factor $\left(\mathrm{k}_{\mathrm{o}}\right)$ is strongly corre336 lated with the inhibition term for NR1. The two parameters in the NR2 inhibition term $\left(\alpha_{N R_{2}}\right.$ and $\left.\beta_{N R 2}\right)$ are strongly corre337 lated. The same can be said regarding the parameters governing the yield distribution for the gasses (Equation 11).

\section{Conclusions}

A continuous lumping model was successfully applied to hydrocracking of VGO feedstock on zeolite catalysts. The second reactor in a two-stage hydrocracking process was simulated. The model contains inhibition terms for $\mathrm{NH}_{3}$ carried over from the pretreatment reactor $(\mathrm{R} 1)$, as well as the residual organic nitrogen in the feed of the hydrocracking reactor (R2). A gamma function was used for the continuous reactivity function and a beta distribution was used for the yield distribution.

344 The 12 model parameters were identified using a calibration database with 52 data points. Parameter identification was 345 performed using 96 sets of randomized initial parameters. The model was then used to simulate a validation database with 22 additional data points. Good simulation results, in terms of $\mathrm{X}_{370+}$ and yield structure were obtained. The model performed less reliably in the case of high conversion $\left(\mathrm{X}_{370+}>90 \%\right)$.

A statistical parameters analysis, based on the Eigenvectors of the Hessian around the optimum was presented. This allowed the parameters with the largest impact on the objective function to be identified. An analysis of the correlation between the parameters was also presented. The eigenvector analysis was used to show that the nitrogen inhibition terms have (NR1 and NR2) have a dominating effect on the target function. This makes it clear that the inclusion of these terms is absolutely necessary to correctly simulate hydrocracking of feeds with different nitrogen content and different levels of pre-treatment. Furthermore, a strong correlation between the nitrogen (NR1) inhibit terms and the pre-exponential factor has been shown.

\section{References}

$357 \quad$ [1] Ward JW. Hydrocracking processes and catalysts. Fuel Process Technol 1993;35:55-85. 
[2] MOTAGHI M, ULRICH B, SUBRAMANIAN A. Slurry-phase hydrocracking - possible solution to refining margins: Opportunity crudes require more hydrogen addition to upgrade orphan product streams into higher-value "clean" products. Hydrocarb Process n.d.;90.

[3] BUTLER G, SPENCER R, COOK B, RING Z, SCHLEIFFER A, RUPF M. Maximize liquid yield from extra heavy oil: Next-generation hydrocracking processes increase conversion of residues. Hydrocarb Process n.d.;88:51-5.

[4] Riazi MR. Characterization and Properties of Pretroleum Fractions. 1st ed. West Conshohocken, PA, USA: 2005.

[5] Rana MS, Sámano V, Ancheyta J, Diaz J a. I. A review of recent advances on process technologies for upgrading of heavy oils and residua. Fuel 2007;86:1216-31. doi:10.1016/j.fuel.2006.08.004.

[6] Catalyse acido-basique. - MARCILLY Christian. 2003.

[7] Weitkamp J. Catalytic Hydrocracking-Mechanisms and Versatility of the Process. ChemCatChem 2012;4:292-306. doi:10.1002/cctc.201100315.

[8] Scherzer J, Gruia AJ. Hydrocracking Science and Technology. New York: CRC Press; 1996.

[9] Martens JA, Jacobs PA, Weitkamp J. Attempts to Rationalize the Distribution of Hydrocracking Products. I Qualitative Description of the Primary Hydrocracking Modes of Long Chain Paraffins in open Zeolites 1986;20:239-81.

[10] Henry R, Tayakout-Fayolle M, Afanasiev P, Lorentz C, Lapisardi G, Pirngruber G. Vacuum gas oil hydrocracking performance of bifunctional Mo/Y zeolite catalysts in a semi-batch reactor. Catal Today 2014;220-222:159-67. doi:10.1016/j.cattod.2013.06.024.

[11] Burnens G, Bouchy C, Guillon E, Martens J a. Hydrocracking reaction pathways of 2,6,10,14tetramethylpentadecane model molecule on bifunctional silica-alumina and ultrastable Y zeolite catalysts. J Catal 2011;282:145-54. doi:10.1016/j.jcat.2011.06.007.

[12] Roussel M. Mechanisms of n-decane hydrocracking on a sulfided NiW on silica-alumina catalyst. J Catal 2003;218:427-37. doi:10.1016/Soo21-9517(03)00164-7.

[13] Francis J, Guillon E, Bats N, Pichon C, Corma a., Simon LJ. Design of improved hydrocracking catalysts by increasing the proximity between acid and metallic sites. Appl Catal A Gen 2011;409-410:140-7. doi:10.1016/j.apcata.2011.09.040.

[14] Pellegrini L, Locatelli S, Rasella S, Bonomi S, Calemma V. Modeling of Fischer-Tropsch products hydrocracking. Chem Eng Sci 2004;59:4781-7. doi:10.1016/j.ces.2004.08.027.

[15] Browarzik D, Kehlen H. Hydrocracking process of $n$-alkanes by continuous kinetics. Chem Eng Sci 1994;49:923-6. doi:10.1016/0009-2509(94)80031-6.

[16] Botchwey C, Dalai AK, Adjaye J. Product Selectivity during Hydrotreating and Mild Hydrocracking of Bitumen-Derived Gas Oil. Energy \& Fuels 2003;17:1372-81. doi:10.1021/efo20214x.

[17] Sanchez S, Rodrıguez MA, Ancheyta J. Kinetic Model for Moderate Hydrocracking of Heavy Oils. Ind Eng Chem Res 2005:9409-13.

[18] Dry ME. High quality diesel via the Fischer-Tropsch process - a review. J Chem Technol Biotechnol 2002;77:43-50. doi:10.1002/jctb.527. 
[19] Choudhary N, Saraf DN. Hydrocracking: A Review. Ind Eng Chem Prod Res Dev 1975;14:74-83. doi:10.1021/i360054aoo2.

[20] Calemma V, Gambaro C, Parker WO, Carbone R, Giardino R, Scorletti P. Middle distillates from hydrocracking of FT waxes: Composition, characteristics and emission properties. Catal Today 2010;149:406. doi:10.1016/j.cattod.2009.03.018.

[21] Ancheyta J, Sánchez S, Rodríguez M a. Kinetic modeling of hydrocracking of heavy oil fractions: A review. Catal Today 2005;109:76-92. doi:10.1016/j.cattod.2005.08.015.

[22] Becker PJ, Celse B, Guillaume D, Dulot H, Costa V. Hydrotreatment modeling for a variety of VGO feedstocks: A continuous lumping approach. Fuel 2015;139:133-43. doi:10.1016/j.fuel.2014.08.032.

[23] Kumar A, Sinha S. STEADY STATE MODELING AND SIMULATION OF HYDROCRACKING REACTOR. Pet Coal 2012;54:59-64.

[24] Elizalde I, Ancheyta J. Modeling the simultaneous hydrodesulfurization and hydrocracking of heavy residue oil by using the continuous kinetic lumping approach. Energy and Fuels 2012;26:1999-2004 . doi:10.1021/ef201916s.

[25] Qader SA, Hill GR. Hydrocracking of Petroleum and Coal Oils. Ind Eng Chem Process Des Dev 1969;8:462-9. doi:10.1021/i260032aoo5.

[26] Krishna R, Saxena AK. Use of an axial-dispersion model for kinetic description of hydrocracking. Chem Eng Sci 1989;44:703-12. doi:10.1016/ooo9-2509(89)85045-6.

[27] Lababidi HMS, AlHumaidan FS. Modeling the hydrocracking kinetics of atmospheric residue in hydrotreating processes by the continuous lumping approach. Energy and Fuels 2011;25:1939-49. doi:10.1021/ef200153p.

[28] Govindhakannan J, Riggs JB. On the construction of a continuous concentration-reactivity function for the continuum lumping approach. Ind Eng Chem Res 2007;46:1653-6. doi:10.1021/ieo6o7191.

[29] Elkamel A, Al-Ajmi A, Fahim M. MODELING THE HYDROCRACKING PROCESS USING ARTIFICIAL NEURAL NETWORKS. Pet Sci Technol 1999;17:931-54. doi:10.108o/10916469908949757.

[30] Laxmi Narasimhan CS, Thybaut JW, Marin GB, Denayer JF, Baron GV, Martens J a., et al. Relumped singleevent microkinetic model for alkane hydrocracking on shape-selective catalysts: catalysis on ZSM-22 pore mouths, bridge acid sites and micropores. Chem Eng Sci 2004;59:4765-72. doi:10.1016/j.ces.2004.07.093.

[31] Martens G, Froment GF. Kinetic Modeling of Paraffins Hydrocracking based upon Elementary Steps and the Single Event Concept. Stud Surf Sci Catal 1999;122:333-40.

[32] Guillaume D, Valéry E, Verstraete JJ, Surla K, Galtier P, Schweich D. Single Event Kinetic Modelling without Explicit Generation of Large Networks: Application to Hydrocracking of Long Paraffins. Oil Gas Sci Technol - Rev d'IFP Energies Nouv 2011;66:399-422. doi:10.2516/ogst/2011118.

[33] Surla K, Guillaume D, Verstraete JJ, Galtier P. Kinetic Modeling using the Single-Event Methodology: Application to the Isomerization of Light Paraffins. Oil Gas Sci Technol - Rev d'IFP Energies Nouv 2011;66:343-65. doi:10.2516/ogst/2011119.

[34] ASTM D3238 - 95(2010) Standard Test Method for Calculation of Carbon Distribution and Structural Group Analysis of Petroleum Oils by the n d M Method n.d. http://www.astm.org/Standards/D3238.htm (accessed November 24, 2014). 
435 [35] Dennis JE, Gay DM, Welsch RE. Algorithm 573: NL2SOL---An Adaptive Nonlinear Least-Squares Algorithm [E4]. ACM Trans Math Softw 1981;7:369-83. doi:10.1145/355958.355966. 